came laments from researchers that science would now be the servant of industry and that fundamental research might lose out.

Such reactions are misguided, both as a matter of fact and in principle. Factually, they ignore the track record of the current government, whatever its prevailing structure, in its consistent support for a portfolio of research ranging from the fundamental to the directly applicable. They also do insufficient justice to the two ministers now at the helm of the university and science bases, both of whom are strong advocates for science. The science minister Paul Drayson (who has been given more clout across government than his predecessors in the role) is an articulate businessman who has never lost sight of the fundamental science on which his pharmaceutical company PowderJect was based. And his ministerial boss, Peter Mandelson, is a highly effective politician who is pivotal within the government, and who previously demonstrated an understanding of the needs of science when, in 1998, he was Secretary of State for Trade and Industry and in charge of the government department that was then relevant to science funding.

The reactions to the reshuffle were also misguided in principle. Whether dealing with the Labour government or the Conservative opposition, UK scientists as a whole need to avoid giving the impression that they are impervious to the requirements of the nation and that any outsider should simply give them the money and leave them to get on with it. This will be especially true over the next 12 months, as the country heads towards a general election and as both main political parties plan future expenditures.

None of this is intended to let politicians off the hook. The government needs to articulate more powerfully its vision for the universities, and the Conservative party needs to explain its plan for how science and the universities will be kept robust in the difficult times ahead.

But the science community in any country where national budgets are under extraordinary pressure should be sending coherent positive messages to all political parties. These communities should find fresh language with which to extol the value of research in meeting national challenges. They need to highlight its relevance to a nation's particular economic opportunities, to mitigating and anticipating such effects as climate change and emerging diseases and, yes, to sustaining its vigour and enriching the nation's culture, through fundamental new insights. If, by contrast, researchers and their supporters convey to the public a sense of entitlement, they risk undermining science as a whole.

\section{Degrees of knowledge}

\section{Technology is founded on precision measurements,} and scientists strive to make these ever more exact.

or the nineteenth-century British physicist William Thomson, later Lord Kelvin, the act of measurement was at the heart of science. "Nearly all the grandest discoveries of science have been but the rewards of accurate measurement," he once declared.

It was thus fitting that, in 1954, Kelvin was honoured for his own pioneering work in thermodynamics when the fundamental unit of temperature was named after him. Today, the kelvin stands ready to be redefined (see page 902), thanks to the efforts of researchers who have taken Kelvin's advice to heart and pushed the bounds of precision measurements in ways that he would not have dreamed possible. Working at national standards laboratories in several countries, these scientists do not usually garner the kinds of accolade bestowed on leaders in more prominent fields. But science as a whole should celebrate the work that today's precision metrologists and their forebears have accomplished.

Centuries ago, metrology played a more obvious role in science and in society in general. The Royal Observatory in London and the French Royal Academy of Sciences in Paris were established in the latter part of the seventeenth century in part to pin down measurements of longitude, which was of tremendous practical importance for international commerce. A century later, efforts to standardize the units of measurement led to the adoption of the metric system in France, which replaced units based on inexact anatomical references, such as the foot. That system was eventually enshrined in 1875 by a diplomatic treaty known as the Metre Convention.

By the early twentieth century, countries had developed laboratories devoted to precision metrology, such as the National Physical Laboratory in Teddington, UK, and the US National Bureau of Standards, now renamed the National Institute of Standards and Technology (NIST) and located in Gaithersburg, Maryland. The renaming was not only symbolic; the pursuit of exacting measurement continues to play an important part in the development and proliferation of new technologies. Today, the forefront of metrology enables advances in such varied fields as the semiconductor industry, climate change, biomedical science and the burgeoning area of nanotechnology. At the same time, national metrological labs also carry out important work in basic science. NIST researchers, for example, have shared physics Nobels for the development of laser-based precision spectroscopy, Doppler cooling and the creation of the first Bose-Einstein condensate.

From the vantage point of the average citizen or scientist, the value of refining the units of measurement is not as obvious today as when nations fought over the definition of units in the trade of grain or cloth. We are now in the 'long tail' of improvements, making the tiniest of adjustments to accuracy and precision, and fiddling with subtleties in definition that largely improve the aesthetics of our system of measurement rather than its immediate utility.

But there is intrinsic value in pushing nature to the absolute limits of experimental precision and seeing whether our current understanding cracks. It was precision measurement of the density of nitrogen, for example, that led to the discovery of the element argon. Lord Kelvin, in his presidential address to Britain's Royal Society in 1894, rightly acknowledged that work as the most important scientific discovery of the year. In his address, he referred to something he had said two decades earlier: "Accurate and minute measurement seems to the non-scientific imagination a less lofty and dignified work than looking for something new." But, as today's precision metrologists have shown, many discoveries will no doubt arise from the ongoing desire to express our knowledge in numbers. 